\title{
A transparência das informações epidemiológicas e financeiro-orçamentárias sobre a pandemia da COVID-19 nos governos estaduais brasileiros
}

Maria Paula Almada'

http://orcid.org/0000-0003-0037-614X

\section{Camilo Aggio"}

https://orcid.org/0000-0003-1383-9019

Paula Karini Amorim"'I

https://orcid.org/0000-0002-2909-0500

Nina Santos ${ }^{1}$

https://orcid.org/0000-0002-1944-8599

\section{Maria Dominguez Costa Pinho'}

https://orcid.org/0000-0003-2339-5570

I - Instituto Nacional de Ciência e Tecnologia em Democracia Digital. Salvador (BA). Brasil.

II - Universidade Federal de Minas Gerais.

Belo Horizonte (MG). Brasil.

III - Instituto Federal do Tocantins.

Palmas (TO). Brasil. 
Resumo: Este artigo avalia os níveis de transparência de dados e informações dos governos estaduais e do Distrito Federal (DF) relativos à pandemia da COVID-19. Foram prospectados websites dos estados e DF. Um instrumento metodológico quantitativo e qualitativo foi desenvolvido para categorização e coleta das informações. Avaliou-se a transparência das informações epidemiológicas e financeiro-orçamentárias relativas à pandemia da COVID-19. Posteriormente, verificou-se se variáveis socioeconômicas e epidemiológicas podem explicar o índice de transparência dos governos estaduais, mas os testes não revelaram causalidade entre tais variáveis e os índices de transparência. Ao contrário do esperado, os estados brasileiros publicam mais informações sobre dados da pandemia e dados que auxiliam a tomada de decisão por parte dos gestores do que informações financeiro-orçamentárias. Treze estados apresentaram transparência avançada, treze, transparência moderada e um, transparência fraca. IDH e renda mensal são as que explicam os níveis de transparência aferidos.

Palavras-chave: transparência de dados; Brasil; governos estaduais; pandemia COVID-19; websites dos estados.

\begin{abstract}
Transparency of epidemiological and financial-budget information on the COVID-19 pandemic in Brazilian state governments - This paper evaluates the levels of data and information transparency of state governments and the Federal District (DF) regarding the COVID-19 pandemic. Websites of the states and DF were prospected. A quantitative qualitative methodological instrument was developed for categorizing and collecting the information. The transparency of epidemiological and financial-budgetary information regarding the COVID-19 pandemic was assessed. Subsequently, it was verified whether socioeconomic and epidemiological variables can explain the transparency index of state governments, but the tests did not reveal causality between such variables and the transparency indexes. Contrary to what was expected, Brazilian states publish more information about pandemic data and data that helps managers' decision making than financial-budgetary information. Thirteen of the states showed advanced transparency, and 13 moderate transparency and one, poor transparency. HDI and monthly income are the variables that explain the levels of transparency measured.
\end{abstract}

Keywords: data transparency; Brazil; state governments; COVID-19 pandemic; states' websites.

\title{
Introdução
}

Assim como uma série de países, o Brasil vem lidando com os desafios impostos pela circulação de informações inverídicas, falsas, fake news, conteúdos desvinculados de fatos e comprovações científicas, primordialmente por meio das redes digitais de comunicação. O fenômeno, comumente chamado de desinformação, que tem sua origem nas disputas políticas e ideológicas 
em ambientes digitais com ênfase em períodos eleitorais, se estendeu e também contaminou as dinâmicas de produção e consumo de informação e de interações sociais relacionadas à pandemia da COVID-19 (RECUERO; SOARES, 2020; MACHADO et al., 2020).

Nesse contexto, o Brasil detém peculiaridades em relação aos demais países por duas razões interdependentes: (1) o Governo Federal brasileiro tornouse um aliado e patrocinador negacionista das teses anticientíficas sobre a pandemia da COVID-19 e seus efeitos, com implicações diretas em decisões sobre a adoção de medidas de combate à crise sanitária e da cooperação social por meio do esclarecimento da população; e (2) o mesmo governo, por meio do Ministério da Saúde e outros órgãos, adotou medidas que colocaram em xeque a produção de transparência sobre informações fundamentais e atualizadas acerca dos avanços e consequências da pandemia a ponto de provocar a reação de seis veículos de imprensa do País, que formaram um consórcio inédito com o intuito de interpretar e divulgar informações sobre a crise do coronavírus como compensação à política de opacidade adotada pelo Governo Federal.

O consórcio de veículos de comunicação mencionado (que envolve Folha, UOL, O Estado de S. Paulo, Extra, O Globo e G1) assumiu a função que é de competência do Executivo Federal no contexto da crise sanitária: publicar dados atualizados e produzir transparência sobre aquilo que é de interesse da comunidade política. Os seis veículos de imprensa adotaram como estratégia de ação diária a coleta, organização, interpretação e divulgação de dados e informações tornados disponíveis pelas secretarias de saúde dos governos estaduais. As fontes de informação escolhidas pelo consórcio midiático também possuem uma função explicativa do contexto brasileiro: a grande maioria dos entes federativos têm sido alvo de ataques por parte do Governo Federal e do presidente da República em razão da adoção de medidas no combate ao coronavírus, a exemplo do isolamento social irrestrito. Tais embates se estenderam a disputas judiciais em que o Supremo Tribunal Federal decidiu que os entes federativos possuem autonomia em relação ao Executivo Federal para determinar quais políticas julgam adequadas para cuidar de suas populações. Os governos estaduais, portanto, têm se apresentado como polos de inflexão e de resistência às pregações e medidas presidenciais negacionistas e anticientíficas, inclusive no âmbito da divulgação de dados e informações sobre a crise do coronavírus. 
É, portanto, diante desse complexo e controverso cenário que a proposta deste artigo se insere. Considerando que a transparência pública é um elemento indispensável para munir ações de controle social, detectar irregularidades nas compras públicas e orientar melhores políticas de enfrentamento à pandemia, diante de uma crise sanitária de proporções devastadoras como a atual, o instrumento se torna ainda mais imprescindível para ajudar a conter danos que podem se tornar irreparáveis. Propõe-se, portanto, investigar quais os níveis de transparência dos dados e informações dos governos estaduais e do DF em relação à crise da COVID-19 por meio de um modelo teóricometodológico desenvolvido pelas autoras.

O artigo se inicia por meio de uma revisão bibliográfica que aborda a transparência pública on line e o contexto da pandemia da COVID-19 no Brasil. Em seguida, são apresentados o objetivo do estudo, a questão de pesquisa e as hipóteses que norteiam o trabalho. Apresenta-se o instrumento metodológico desenvolvido para avaliar qual o nível de transparência dos estados brasileiros e do DF, que é composto por duas dimensões que avaliam a transparência (1) de casos epidemiológicos e de informações para a tomada de decisões e (2) de informações financeiro-orçamentárias. Busca-se averiguar, ainda, se variáveis socioeconômicas (IDH, PIB, renda mensal, densidade populacional) e epidemiológicas (óbitos, casos por 100 mil habitantes, testes por 100 mil habitantes e letalidade) dos estados e DF ajudam a explicar os índices de transparência dos dados e informações da pandemia da COVID-19 verificados pelo estudo.

\section{Transparência on line e a COVID-19 no Brasil}

Com a popularização da internet, os ambientes, ferramentas e iniciativas digitais passaram a oferecer novas possibilidades para a produção de transparência sobre os negócios públicos. Nesse sentido, o conceito de transparência digital se refere ao emprego de tecnologias da informação e comunicação e dos ambientes digitais para otimizar o fornecimento e o acesso às informações públicas. É por meio das redes digitais que informações públicas passaram a ser acessadas de forma mais rápida, em diferentes sites e portais governamentais, e conduziram ao crescimento significativo do volume de bases de dados públicos, além de interfaces de visualização que tornam esses dados mais inteligíveis.

Nesse contexto, é relevante não apenas o volume de informações públicas ofertadas aos cidadãos, mas também os formatos em que esses dados 
são publicados. Para que sejam livremente compartilhados e analisados, e assim, reaproveitados para inúmeros fins, inclusive para a análise e avaliação de políticas e serviços públicos, convencionou-se que esses dados seguiriam o formato aberto'. Dados abertos governamentais são, então, dados públicos, produzidos a partir das funções administrativas e governamentais, disponíveis em padrões e licenças específicas que permitem a sua reutilização. Esses dados, dotados de valor e interesse público, passaram a ser um dos principais aliados da produção de mais transparência por governos ao redor do mundo.

No Brasil, há pelo menos duas décadas, a oferta de informações públicas passou a ser regulamentada por marcos legais que consideram, inclusive, o ambiente on line como um dos principais meios de divulgação das informações governamentais. Temos, no âmbito da transparência fiscal, a Lei Complementar $n^{\circ}$ 101/2000 (Lei de Responsabilidade Fiscal - LRF) e a Lei Complementar $n^{\circ} .131 / 2009$ (conhecida como Lei da Transparência, que consiste em um adendo à LRF), sendo que ambas tratam da transparência ativa. Poucos anos após a promulgação da Lei da Transparência, tivemos a promulgação da Lei de Acesso à Informação (Lei n 12.527/2011) que se refere às informações que cidadãos ou quaisquer interessados podem solicitar por meio do sistema eSic. Mais recentemente, foi publicado o Decreto 8.777/2016, que editou a Política de Dados Abertos do Poder Executivo Federal.

Desde que a Organização Mundial de Saúde (OMS) declarou, no dia 11 de março de 2020, que o estágio da contaminação da COVID-19, doença causada pelo novo coronavírus (Sars-Cov-2), havia sido elevado ao estado de pandemia, governos, dos níveis locais aos nacionais, tornaram o combate à COVID-19 a prioridade em suas agendas (CHENG; SHAN, 2020). No que tange à transparência pública e ao provimento de informações sobre a pandemia aos cidadãos, tornou-se, por parte dos governos, tão importante quanto necessário divulgar, o mais detalhadamente possível, informações epidemiológicas (número de infectados, óbitos, testes, etc.), aquelas que auxiliam gestores nas tomadas de decisão (taxas de ocupação de leitos, por exemplo), além dos dados financeiro-orçamentárias (doações, aquisições emergenciais e transferências de recursos) relacionados à COVID-19 (HENKE; KELSEY, 2011).

Argumentamos que a transparência pública passa a ser particularmente relevante nesse contexto para: (i) orientar ações futuras da gestão pública para

1 Entre os principais requisitos técnicos dos dados abertos, estão os Oito Princípios dos Dados Abertos Governamentais. Há mais informações sobre cada um desses princípios em: <https://opengovdata.org>. 
o enfrentamento da pandemia e a formulação de políticas públicas baseadas em evidências (GAO; YU, 2020; O'MALLEY et al., 2009; RAJAN et al., 2020); (ii) a identificação da população mais vulnerável e localizações mais atingidas pelo vírus (RAHIMI; ABADI, 2020); (iii), a identificação de como o governo conduz a situação e aplica os recursos destinados à pandemia, para avaliação da atuação do governo, compreensão da real gravidade da situação e tomada de medidas preventivas, como o isolamento social (BARTON et al., 2020; OJIAGU et al., 2020); (iv) o monitoramento das compras emergenciais e mitigação de riscos de desvios e irregularidades (SRIDHAR; BATNIJI, 2008), (v) a apropriação desses dados por jornalistas, pesquisadores e organizações da sociedade civil para a promoção do controle social, produção de pesquisas científicas e a ampla publicação de informações sobre a pandemia (LA et al., 2020); e, enfim; (vi) a criação de estratégias de enfrentamento para, por exemplo, a retomada de atividades e o fim de medidas de quarentena (ALWAN et al., 2020).

Para além do provimento de informações epidemiológicas e financeiro-orçamentárias, torna-se imprescindível que tais informações estejam disponíveis aos cidadãos com atualizações frequentes. A denominada transparência em tempo real implica na divulgação contínua dos processos internos, dados e prestação de contas do governo no mesmo momento em que acontecem (AMORIM, 2012). É o tipo de transparência que precisa ser adotado por governos frente à pandemia por impactar nas tomadas de decisão, sobretudo quando se trata de situações emergenciais em que as informações precisam estar acessíveis para a rápida adoção de medidas de contenção. É diferente da chamada transparência retrospectiva, que se refere à prestação de contas ex post pela administração pública e que, embora seja importante para a avaliação das ações do governo, não traz vantagens para a rápida tomada de decisões em contextos emergenciais (ALWAN et al., 2020).

Em termos normativos, por meio da Lei Federal n 13.979/2020, as contratações emergenciais de bens e serviços para a contenção da COVID-19 foram regulamentadas. Foram estabelecidas regras excepcionais para essas aquisições, como dispensa de licitação, o que foi seguido também por estados e municípios. Esta legislação prevê, ainda, que seja promovida a transparência das informações relativas às contratações realizadas neste cenário de excepcionalidade.

Apesar da importância da transparência nesse contexto, o Governo Federal brasileiro aponta para retrocessos nesse sentido. Ainda nos primeiros meses 
da crise, em março de 2020, o presidente Jair Bolsonaro editou a Medida Provisória 928/2020², que previa a suspensão dos prazos de respostas de pedidos via Lei de Acesso à Informação por todos os órgãos e entidades da Administração Pública Federal nas áreas em que não houvesse atendimento presencial, por conta do regime de teletrabalho dos servidores, além de suspender a possibilidade recursal. O Supremo Tribunal Federal, no entanto, suspendeu a MP em seguida.

Mesmo com o aumento do número de mortes e de infectados, a gestão federal foi minando cada vez mais a transparência até chegar ao ponto de sonegar dados, atrasar a atualização diária de boletins epidemiológi$\cos ^{3}$, retirar informações do ar, e deixar de divulgar a quantidade total de infectados e de óbitos ${ }^{4}$. O Portal do Ministério da Saúde, com dados sobre a pandemia, foi retirado do ar no dia 05 de junho ${ }^{5}$ e só se tornou acessível no dia seguinte, sem dados agregados que apresentassem o número total de óbitos e infectados pela COVID-19. Os dados agregados sobre o coronavírus só voltaram a ser exibidos após decisão do STF.

Com a imprevisibilidade quanto ao provimento de informações detalhadas e atualizadas sobre a pandemia por parte do Governo Federal, torna-se ainda mais importante que outros níveis de governo, notadamente os governos municipais e estaduais, publiquem dados sobre o avanço da pandemia por meio dos seus portais. Nesse sentido, o STF compreendeu que a autonomia para legislar sobre as medidas de contenção da pandemia é de cada estado e município, que passaram a não depender da União para tomar decisões de contenção da crise ${ }^{6}$. É por meio das informações das secretarias de saúde estaduais e municipais, por exemplo, que têm surgido iniciativas da imprensa e da sociedade civil para tornar os dados disponíveis inteligíveis e munir os cidadãos de informações precisas sobre a pandemia e suas consequências no Brasil.

\footnotetext{
2 A MP 928/2020 pode ser acessada em: <http://www.in.gov.br/en/web/dou/-/medida-provisorian-928-de-23-de-marco-de-2020-249317429>. Acesso em: 30 jun. 2020.

3 Mais informações em: <https://www.nexojornal.com.br/expresso/2020/06/04/Qual-o-impactodos-atrasos-nos-dados-di\%C3\%A1 rios-da-COVID-19>. Acesso em: 30 jun. 2020.

4 Mais informações em: <https://brasil.elpais.com/brasil/2020-06-06/governo-bolsonaro-impoeapagao-de-dados-sobre-a-COVID-19-no-brasil-em-meio-a-disparada-das-mortes.html>. Acesso em: 30 jun. 2020.

5 Mais informações em: <https://noticias.uol.com.br/ultimas-noticias/ansa/2020/06/06/ministerio-da-saude-tira-portal-com-dados-sobre-COVID-do-ar.htm>. Acesso em: 30 jun. 2020.

6 Mais em: <https://www.poder360.com.br/coronavirus/stf-decide-que-estados-e-municipiostem-autonomia-para-impor-isolamento/>. Acesso em: 27 jul. 2020.
} 


\section{Objetivo do estudo, questão de pesquisa e hipóteses}

Este estudo analisa as informações disponíveis nos portais de todos os governos estaduais brasileiros, além do DF. São avaliadas, a partir de um modelo metodológico desenvolvido pelas autoras, a qualidade das informações epidemiológicas, informações para a tomada de decisão e informações financeiro-orçamentárias disponíveis nos portais governamentais para que se possa, ao fim, aferir sobre o nível da transparência dos governos estaduais e do DF durante a pandemia da COVID-19. A questão de pesquisa que norteia esta investigação indaga:

\section{RQ: Quais os níveis de transparência de dados e informações dos governos estaduais e do DF em relação à crise da COVID-19?}

Considerando que no Brasil existem normas legais que asseguram o provimento da transparência fiscal (como a Lei de Acesso à Informação, a LRF e a Lei da Transparência) e que preveem que os governos (federal, estaduais e municipais) devam publicar, com atualizações regulares, informações financeiro-orçamentárias em seus portais, supõe-se que os estados já dispõem de organização, infraestrutura e pessoal capacitado para o provimento de informações desta natureza. Sendo assim, a H1 assume que:

H1: A pontuação das informações financeiro-orçamentárias (subdimensão 1.3) apresenta média maior que a pontuação das informações epidemiológicas e para tomada de decisão (subdimensões 1.1 e 1.2).

Além disso, buscamos avaliar se, e de que maneira, variáveis socioeconômicas (IDH, PIB, renda mensal, densidade populacional) e epidemiológicas (óbitos, casos por 100 mil habitantes, testes por 100 mil habitantes e letalidade) podem explicar o índice de transparência das informações epidemiológicas e financeiroorçamentárias da pandemia da COVID-19 dos governos estaduais e do DF.

Amorim (2012) testou o cruzamento dos níveis de transparência digital em governos municipais brasileiros com variáveis socioeconômicas, chegando a correlações positivas em alguns casos como o IDH, PIB e densidade populacional. Neste artigo, testamos se esse conjunto de indicadores socioeconômicos apresenta correlações significativas com a transparência digital nos estados considerando, dessa vez, o contexto excepcional de uma pandemia. Assim, temos: 
H2: O índice de transparência das informações epidemiológicas e financeiro-orçamentárias da pandemia COVID-19 dos governos estaduais pode ser explicado pelas variáveis socioeconômicas (IDH, PIB, renda mensal, densidade populacional).

H3: O índice de transparência das informações epidemiológicas e financeiro-orçamentárias da pandemia COVID-19 dos governos estaduais pode ser explicado pelas variáveis epidemiológicas (óbitos, casos por 100 mil habitantes, testes por 100 mil habitantes e letalidade).

\section{Metodologia}

Nesta seção, são apresentados os procedimentos metodológicos da pesquisa em dois pontos: (i) a escolha das dimensões, dos indicadores e conceitos do instrumento metodológico; e (ii) o tempo e registro de achados da navegação pelos portais governamentais.

\section{Sobre o instrumento metodológico: escolha das dimensões, dos indicadores e conceitos}

Neste estudo, os indicadores e critérios do instrumento metodológico foram organizados em duas dimensões: 1) informações epidemiológicas e 2) informações financeiro-orçamentárias. Na primeira dimensão estão as informações monitoradas pela Secretaria de Vigilância em Saúde e DATASUS do Ministério da Saúde, além das informações sobre medidas de prevenção, campanhas e legislação sobre o assunto publicadas pelos estados e governo federal. Na outra dimensão estão as informações já consagradas na legislação brasileira como obrigatórias para a transparência pública, tais como Lei de Responsabilidade Fiscal, Lei da Transparência e a Lei 13.979/2020. Assumindo que informação é a matéria-prima da publicidade e da transparência, a qualidade da informação publicada é fundamental para se alcançar a efetividade do princípio da transparência digital pelos governos. Existem alguns atributos considerados essenciais para que a informação seja um insumo de qualidade e que, portanto, possa produzir mais e melhor transparência. São eles: tempo, conteúdo e forma.

\section{Quanto ao atributo tempo}

A informação pública deve estar disponível em tempo hábil, estar atualizada, e cobrir os períodos do passado, presente e futuro. Assim, para este estudo, considerando o contexto emergencial imposto pela pandemia, consideramos como atualizadas as informações apresentadas nas páginas principal ou secundária: em tempo real para a atualização dos indicadores de despesas e 
receitas no portal; a cada 24 horas para a atualização das informações epidemiológicas e informações de saúde para a tomada de decisão no portal e a cada 7 dias para a atualização dos indicadores de contratações emergenciais e doações.

\section{Quanto ao atributo conteúdo}

A informação deve ser precisa e estar isenta de erros, ser completa, ter alcance e desempenho de modo a permitir mensurar o seu progresso. Assim, consideramos que as informações atendem à exigência do atributo conteúdo quando demonstrarem, junto à sua publicação, a fonte principal, a data da publicação, valores diários e acumulados e progressos (ou resultados) alcançados.

\section{Quanto ao atributo forma}

Consideramos que as informações atendem aos quesitos relacionados à forma quando apresentam uma linguagem direta e de fácil compreensão. Quando for necessário o uso de termos técnicos, devem ser utilizados glossários, dicionários ou legendas. E ainda que esteja organizada numa sequência lógica, buscamos pelo menos duas formas de apresentação (textos/números, gráficos, infográficos, visualização por dashboards, painel, mapas, ou áudio). Por fim, foi avaliado se os dados estavam publicados em formatos abertos (como CSV, JSON, RDF, ODS, entre outros).

\section{Quanto ao cálculo do índice de transparência}

Entendemos que tanto a transparência sobre informações epidemiológicas e para tomada de decisão (Dimensão 1) quanto sobre informações financeiroorçamentárias (Dimensão 2) são igualmente importantes para avaliar o nível de transparência de determinado estado sobre a pandemia da COVID-19. Por esta razão, optamos por não atribuir diferentes pesos às referidas dimensões. O cálculo será feito por meio da média ponderada dos indicadores. Mediante a apuração dos resultados dos pontos atribuídos às dimensões serão considerados os seguintes conceitos:

\begin{tabular}{|c|c|c|}
\hline Conceito global & Escala de pontuação & Escala percentual \\
\hline TA - transparência avançada & 4 a 3,2 & $100 \%$ a $80 \%$ \\
\hline TM - transparência moderada & 3,1 a 2,4 & $79,9 \%$ a $60 \%$ \\
\hline TF - transparência fraca & 2,3 a 1,6 & $59,9 \%$ a $40 \%$ \\
\hline OS - opacidade significativa & 1,5 a 0,8 & $39,9 \%$ a $20 \%$ \\
\hline OA - opacidade avançada & Abaixo de 0,7 & Abaixo de $19,9 \%$ \\
\hline
\end{tabular}

Tabela 1. Classificação da transparência a partir das escalas de pontuação e percentual. Fonte: Adaptação Amorim, 2012; Almada, 2017. 
Ainda sobre o processo de avaliação dos indicadores realizado por meio da navegação orientada, esclarecemos que este foi conduzido por dois codificadores. Primeiramente, cada codificador atribuiu os conceitos conforme seu julgamento. Após esta avaliação individual, as notas foram tabeladas lado a lado. O total de notas atribuídas pelos codificadores foi de 1.026 (19 quesitos $\times 27$ estados da federação). Foram identificados apenas 14 itens com discordância quando comparamos as notas atribuídas pelos codificadores. Assim, houve um total de 27 discordâncias, contra 999 concordâncias. Seguindo a técnica da porcentagem de concordância, verificamos que o grau de confiabilidade da avaliação foi de $97,37 \%$. Portanto, este percentual demonstra um alto grau de confiabilidade nos resultados encontrados.

\section{Transparência digital dos estados sobre a COVID-19}

\section{Dimensão epidemiológica}

\section{Informações epidemiológicas}

\begin{tabular}{|c|c|}
\hline Indicadores & Conceito e descrição \\
\hline Casos confirmados & $\begin{array}{l}4 \text { - Informação encontrada na página principal ou secundária e atualizada a cada } 24 \\
\text { horas. } \\
2 \text { - Informação encontrada em página terciária ou desatualizada. } \\
0 \text { - Informação não encontrada }\end{array}$ \\
\hline $\begin{array}{l}\text { Casos em } \\
\text { investigação }\end{array}$ & $\begin{array}{l}4 \text { - Informação encontrada na página principal ou secundária e atualizada a cada } 24 \\
\text { horas. } \\
2 \text { - Informação encontrada em página terciária ou desatualizada. } \\
0 \text { - Informação não encontrada }\end{array}$ \\
\hline Recuperados & $\begin{array}{l}4 \text { - Informação sobre casos recuperados ou alta médica encontrada na página } \\
\text { principal ou secundária e atualizada a cada } 24 \text { horas. } \\
2 \text { - Informação encontrada em página terciária ou desatualizada. } \\
0 \text { - Informação não encontrada }\end{array}$ \\
\hline Óbitos & $\begin{array}{l}4 \text { - Informação encontrada na página principal ou secundária e atualizada a cada } 24 \\
\text { horas. } \\
2 \text { - Informação encontrada em página terciária ou desatualizada. } \\
0 \text { - Informação não encontrada }\end{array}$ \\
\hline $\begin{array}{l}\text { Localização } \\
\text { (municípios) }\end{array}$ & $\begin{array}{l}4 \text { - Informação encontrada na página principal ou secundária e atualizada a cada } 24 \\
\text { horas. } \\
2 \text { - Informação encontrada em página terciária ou desatualizada. } \\
0 \text { - Informação não encontrada }\end{array}$ \\
\hline $\begin{array}{l}\text { Dados em formato } \\
\text { aberto }\end{array}$ & $\begin{array}{l}4 \text { - Dados sobre casos confirmados, óbitos e localização estão em formatos abertos; } \\
2 \text { - Apenas dados sobre casos confirmados estão em formatos abertos; } \\
0 \text { - Não foram encontrados dados em formatos abertos }\end{array}$ \\
\hline
\end{tabular}

Tabela 2. Informações epidemiológicas. Legenda: 0 = não encontrado / 2 = encontrado parcialmente / 4= encontrado. Fonte: Elaboração própria das autoras. 


\section{Informações de saúde para a tomada de decisão}

\begin{tabular}{|c|c|}
\hline Indicadores & Conceito e descrição \\
\hline Ocupação de leitos & $\begin{array}{l}4 \text { - Informação sobre leitos comuns e de UTIs encontrada na página principal ou } \\
\text { secundária e atualizada a cada } 24 \text { horas. } \\
2 \text { - Informação de leitos comuns ou leitos de UTI encontrada em página terciária ou } \\
\text { desatualizada. } \\
0 \text { - informação não encontrada }\end{array}$ \\
\hline Testes realizados & $\begin{array}{l}4 \text { - Informação sobre testes rápidos e PCR encontrada na página principal ou } \\
\text { secundária e atualizada a cada } 24 \text { horas. } \\
2 \text { - Informação sobre a realização de testes rápidos ou de } \mathrm{PCR} \text { encontrada em página } \\
\text { terciária ou desatualizada. } \\
0 \text { - Informação não encontrada }\end{array}$ \\
\hline $\begin{array}{l}\text { Atendimentos em } \\
\text { atenção básica }\end{array}$ & $\begin{array}{l}4 \text { - Informações sobre atendimentos em atenção básica encontradas na página } \\
\text { principal ou secundária e atualizada a cada } 24 \text { horas. } \\
2 \text { - Informação sobre atendimentos em atenção básica em página terciária ou } \\
\text { desatualizada. } \\
0 \text { - Informação não encontrada }\end{array}$ \\
\hline $\begin{array}{l}\text { Microdados de } \\
\text { infectados }\end{array}$ & $\begin{array}{l}4 \text { - Apresenta entre três e quatro dos seguintes itens: informações sobre idade, sexo, } \\
\text { cor da pele/raça, comorbidades de pacientes infectados atendem a todos os atributos } \\
\text { de tempo, conteúdo e forma. } \\
2 \text { - Apresenta até dois dos itens descritos acima. } \\
0 \text { - Informação não encontrada }\end{array}$ \\
\hline $\begin{array}{c}\text { Medidas } \\
\text { governamentais }\end{array}$ & $\begin{array}{l}4 \text { - Informações sobre legislações, atos, portarias e decretos que delimitam a } \\
\text { quarentena no estado, definem lockdown, atividades essenciais, etc. encontradas na } \\
\text { página principal ou secundária. informação atende a todos os atributos de tempo, } \\
\text { conteúdo e forma. } \\
2 \text { - Informações parciais encontradas em página terciária } \\
0 \text { - Informação não encontrada }\end{array}$ \\
\hline Evolução histórica & $\begin{array}{l}4 \text { - Informações sobre números de casos e óbitos são apresentadas desde o início da } \\
\text { pandemia (tempo) e podem ser visualizadas em dashboards, gráficos, painéis ou } \\
\text { mapas (forma) } \\
2 \text { - Informações sobre casos ou óbitos atendem a pelo menos um atributo (tempo ou } \\
\text { forma) } \\
0 \text { - Informação não encontrada }\end{array}$ \\
\hline Boletins diários & $\begin{array}{l}4 \text { - Informação atende a todos os atributos de tempo, conteúdo e forma. } \\
2 \text { - Informação atende a pelo menos o atributo de tempo. } \\
0 \text { - Informação não encontrada }\end{array}$ \\
\hline $\begin{array}{l}\text { Canais de comunicação } \\
\text { sobre a pandemia } \\
\text { (Ouvidoria) }\end{array}$ & $\begin{array}{l}4 \text { - Há link direto para Canal de Comunicação sobre pandemia (chat, e-mail, fale } \\
\text { conosco, ouvidoria, etc.) na página principal ou secundária } \\
0 \text { - Não há link para Canal de Comunicação sobre pandemia }\end{array}$ \\
\hline $\begin{array}{c}\text { Dados em formato } \\
\text { aberto }\end{array}$ & $\begin{array}{l}4 \text { - Informações sobre microdados (exemplo idade, raça, sexo e comorbidade) e } \\
\text { testes estão em formatos abertos; } \\
2 \text { - Informações sobre microdados ou testes estão em formato aberto } \\
0 \text { - Nenhum dos dois }\end{array}$ \\
\hline
\end{tabular}




\section{Dimensão financeiro-orçamentária}

\section{Informações financeiro-orçamentárias}

\begin{tabular}{|c|l|}
\hline Indicadores & \multicolumn{1}{c|}{ Conceito e descrição } \\
\hline $\begin{array}{c}\text { Contratações realizadas } \\
\text { (inexigibilidade, } \\
\text { dispensa de licitação, } \\
\text { pregão) }\end{array}$ & $\begin{array}{l}4 \text { - Informações sobre contratações realizadas (inexigibilidade, dispensa de } \\
24 \text { horas } \\
2 \text { - Informação incompleta ou encontrada em página terciária ou desatualizada } \\
\text { 0 - Informação não encontrada }\end{array}$ \\
\hline $\begin{array}{c}\text { Gastos / Despesas } \\
\text { 4 - Informação (valores empregados especificamente para o combate à COVID-19 } \\
\text { no estado) encontrada na página principal ou secundária e atualizada em tempo real. } \\
2 \text { - Informação encontrada em página terciária ou desatualizada. } \\
\text { 0 - Informação não encontrada }\end{array}$ \\
\hline $\begin{array}{c}\text { Transferências } \\
\text { programa federativo e } \\
\text { doações }\end{array}$ & $\begin{array}{l}\text { 4 - Informação (valores arrecadados especificamente para o combate à COVID-19 } \\
\text { no estado) encontrada na página principal ou secundária e portal atualizado a cada } \\
24 \text { horas. } \\
2 \text { - Informação encontrada em página terciária ou desatualizada. } \\
0 \text { - Informação não encontrada }\end{array}$ \\
\hline $\begin{array}{c}\text { Dados em formato } \\
\text { aberto }\end{array}$ & $\begin{array}{l}\text { 4 - Dados sobre os quatro itens acima estão em formatos abertos } \\
\text { 2 - Dados sobre até três dos itens acima estão em formatos abertos } \\
\text { 0 - Dados sobre dois ou menos dos itens acima estão em formatos abertos }\end{array}$ \\
\hline
\end{tabular}

Tabela 4. Informações financeiro-orçamentárias. Legenda: 0 = não encontrado / 2 = encontrado parcialmente / 4= encontrado. Fonte: Elaboração própria das autoras.

\section{Dimensão Geral}

\begin{tabular}{|c|c|c|c|}
\hline \multirow{4}{*}{$\begin{array}{c}\text { Variáveis } \\
\text { socioeconômicas }\end{array}$} & IDH & \multirow{2}{*}{$\begin{array}{c}\text { Variáveis } \\
\text { epidemiológicas }\end{array}$} & Óbitos \\
\cline { 2 - 2 } & PIB & Casos por 100 mil habitantes \\
\cline { 2 - 2 } & Renda mensal & Testes por 100 mil habitantes \\
\cline { 2 - 2 } & Densidade Populacional & & Letalidade \\
\hline
\end{tabular}

Tabela 5. Variáveis socioeconômicas e epidemiológicas. Fonte: Elaboração própria das autoras.

\section{Sobre a navegação, tempo e registro dos achados}

A navegação pelos portais governamentais para a coleta dos dados foi realizada entre os dias 2 e 20 de junho de 2020. A atribuição dos conceitos foi realizada por duas codificadoras independentes. Em casos de divergência nas notas atribuídas a cada um dos indicadores, as pesquisadoras debateram sobre as pontuações até chegarem a um consenso para aumentar a confiabilidade da codificação (intercoder reliability).

Para buscar a informação encontrada, as pesquisadoras navegaram pelos seguintes portais, e na seguinte ordem: (i) Portal especial para informações 
sobre a COVID-19 do estado; (ii) Portal da secretaria de saúde do governo; (iii) Portal da transparência do estado; (iv) Portal oficial do governo do estado e (v) Portal de dados abertos do governo estadual. Além disso, alguns estados criaram portais próprios para divulgação de contratações emergenciais, que também foram considerados.

\section{Resultados}

\section{Sobre o índice da transparência}

A navegação pelos 27 portais dos estados e DF para a aplicação do instrumento metodológico e avaliação da disposição de informações sobre a epidemia (informações sobre dados epidemiológicos, que auxiliem os gestores nas tomadas de decisões e financeiro-orçamentárias) nos dá o nível de transparência por estado, classificado, segundo a Tabela 1 (já apresentada), a partir das escalas de pontuação e percentual, variando desde opacidade avançada até transparência avançada.

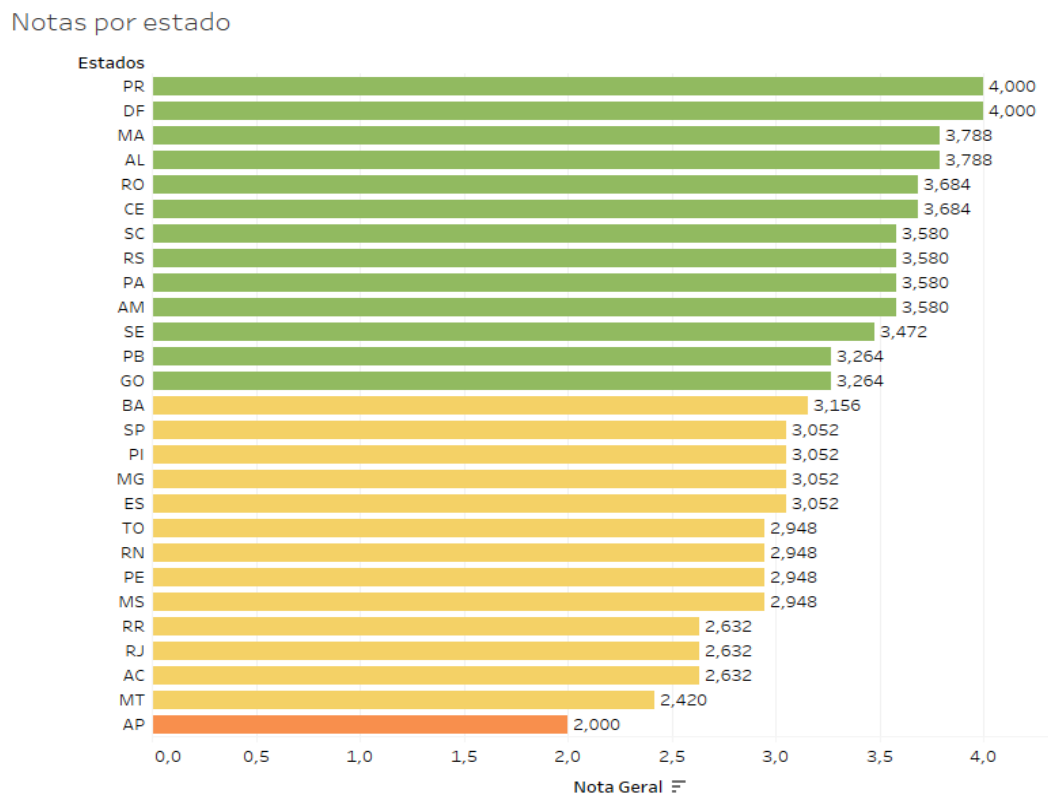

SUM([Nota Geral] $) / 2.5$ for each Estados. Color shows sum of Nota Geral.

Gráfico 1. Notas de transparência obtidas pelos estados e DF. Fonte: Elaboração própria das autoras. 
O Brasil se divide, quase que absolutamente, entre estados com níveis de transparência avançada ou moderada sobre informações acerca da pandemia do coronavírus. Treze estados apresentaram níveis de transparência avançados, treze estados, níveis de transparência moderados e apenas um estado (Amapá) apresentou um nível de transparência fraco, conforme exibe o Gráfico 1.

Dos treze estados com níveis de transparência avançada, cinco são da Região Nordeste, três são da Região Sul, três da Região Norte e dois do Centro-Oeste. Observa-se que nenhum estado sudestino encontra-se nesse patamar, ao passo que todos os três estados da Região Sul figuram no patamar mais avançado de transparência. Dos treze estados com níveis de transparência moderada, quatro são da Região Nordeste, quatro são do Sudeste, três da Região Norte e dois do Centro-Oeste O único estado com nível de transparência fraco se encontra na Região Norte.

Conforme exposto, os índices de transparência dos estados e do DF foram construídos com base no agregado das notas atribuídas aos critérios de cada uma das duas dimensões para cada ente federativo. Para lançar luz acerca do peso que cada uma destas dimensões pode ter dado à classificação dos índices de transparência dos estados e DF, procedemos às análises comparativas por meio da segregação dessas duas dimensões.

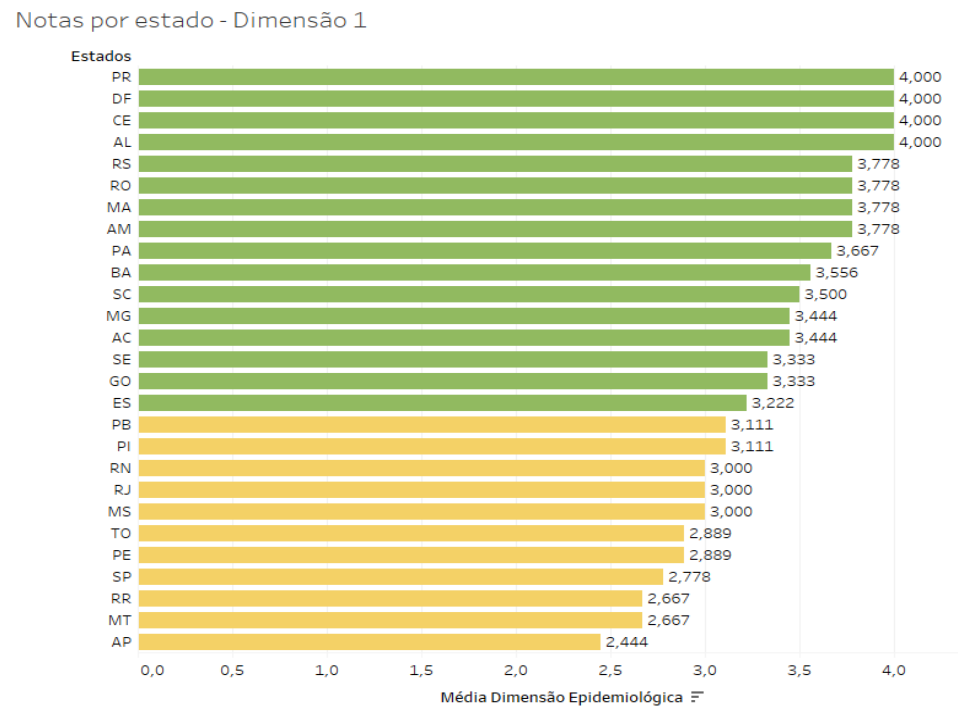

[Média Dimensão 1]/2.5 for each Estados. Color shows Média Dimensão 1. The data is filtered on REGIÕES, which has multiple members selected.

Gráfico 2. Notas de transparência da dimensão Epidemiológica obtidas pelos estados e DF. Fonte: Elaboração própria das autoras. 
Quando considerada apenas a primeira dimensão (informações epidemiológicas), somente cinco estados permanecem na mesma posição: PR e DF se mantêm na primeira e segunda posições respectivamente, os dois estados com o menor índice de transparência geral (MT, AP) e os estados de Alagoas e Pará, que se mantêm nas quarta e nona posições, respectivamente.

Dentre os estados que mais perdem posição, destaca-se São Paulo, com queda de dez posições, ou seja, sugere-se que a posição que o estado ocupa no resultado geral, agregado, decorre, possivelmente, de seu desempenho na segunda dimensão (Gráfico 3). O estado que mais cresce nessa relação comparativa é o Acre, que sobe doze posições, demonstrando o peso significativo de seu desempenho na primeira dimensão.

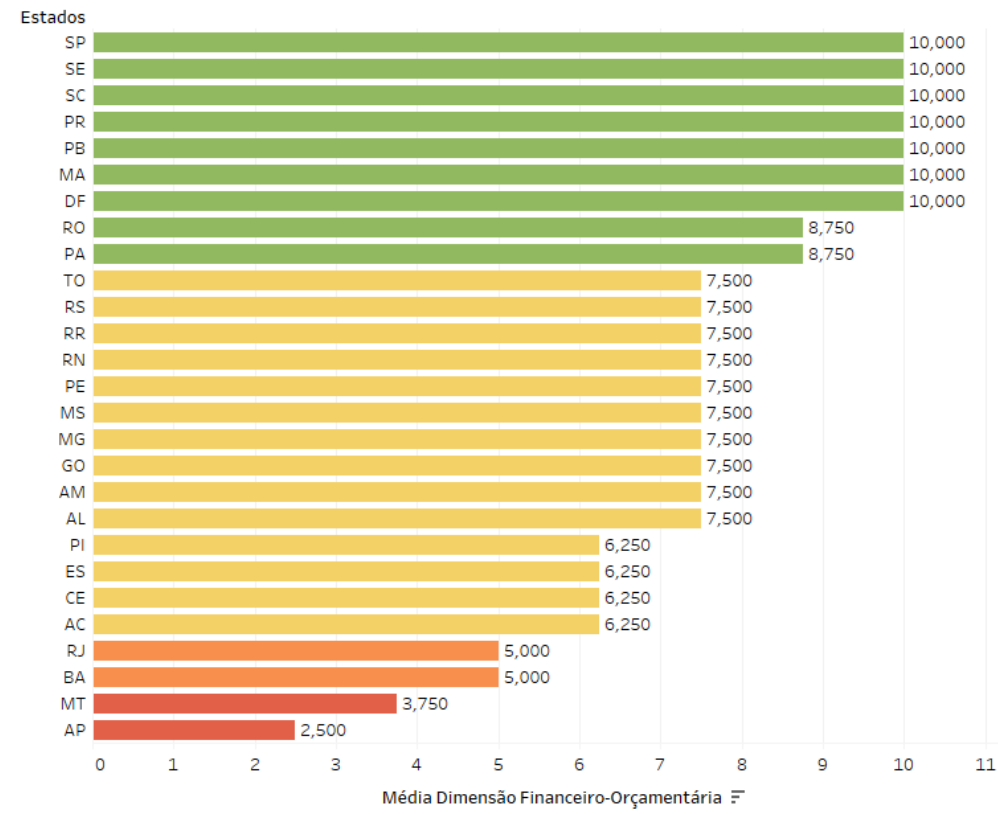

Gráfico 3. Notas de transparência da Dimensão Financeiro-Orçamentária obtidas pelos estados e DF. Fonte: Elaboração própria das autoras.

Quando considerada apenas a Dimensão 2, observa-se ainda mais alterações. Mantiveram suas posições, mais uma vez, os dois estados com o menor índice de transparência geral (MT e AP), os estados do Pará e Rio de Janeiro, que mantiveram a nona e vigésima quarta posições, respectivamente, além de PR e DF, que mantêm a nota máxima. 
Dentre aqueles que possuem as maiores alterações de posição na comparação com o ranking geral, destaca-se, como esperado, o estado de São Paulo, que sobe catorze posições. Um claro sinal de que o peso da transparência financeiro-orçamentária do referido estado é mais relevante para sua classificação geral. No sentido oposto, de descendência, destacam-se os estados do Ceará, Alagoas e Bahia, que descem, respectivamente, 16 e 15 posições em relação às suas pontuações totais.

Nos mapas a seguir, é possível visualizar os níveis de transparência de cada estado e do DF por dimensão, bem como o nível de transparência geral dos estados (llustração 1).

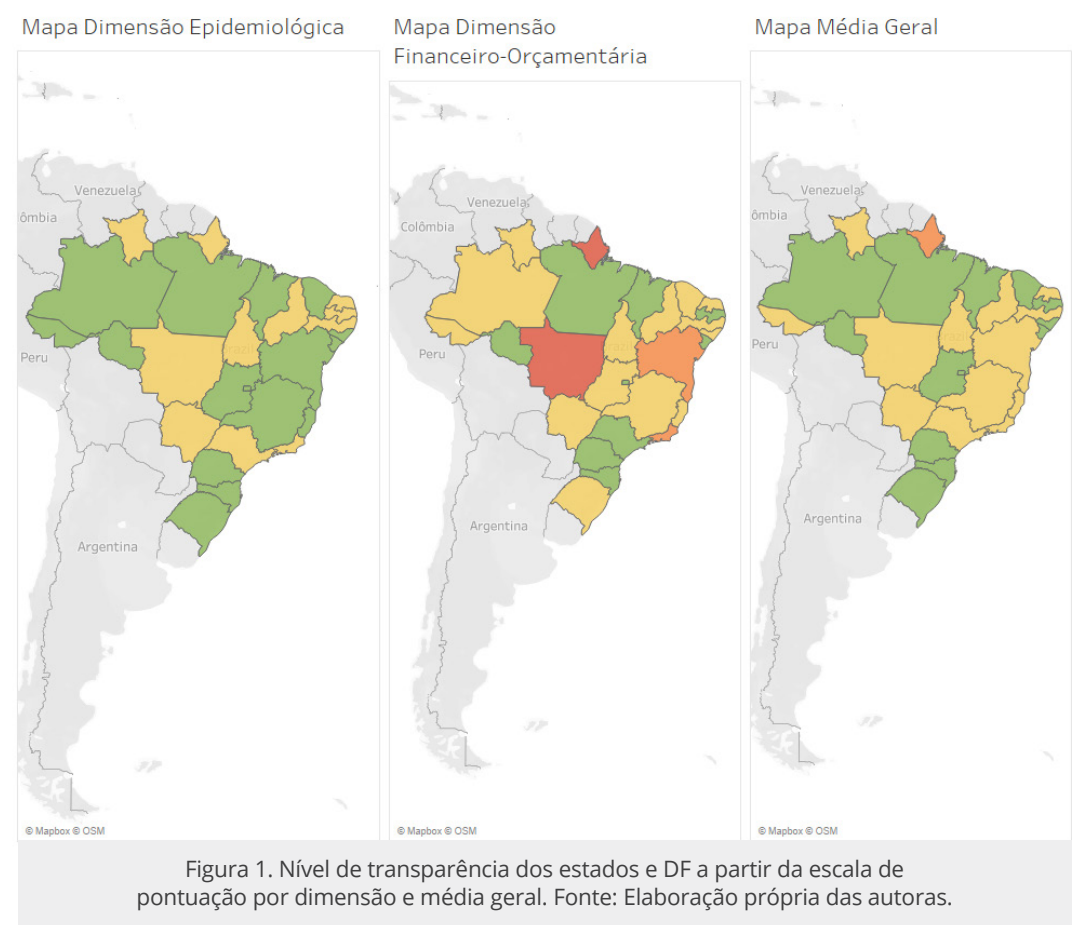

Pode-se concluir diante desses dados e comparações, portanto, que há, de forma geral, um maior investimento na produção e divulgação atualizada de informações epidemiológicas por parte dos entes federativos analisados do que na produção de transparência financeira em relação à pandemia. 


\section{A análise dos dados}

A análise da pontuação média das subdimensões demonstra que as informações epidemiológicas e para a tomada de decisão alcançaram melhores resultados que a subdimensão das informações financeiro-orçamentárias, conforme apresentado na Tabela 6 . No entanto, para testar a hipótese que diz que a pontuação das informações financeiro-orçamentárias (subdimensão 1.3) apresenta média maior que pontuação das informações epidemiológicas e para tomada de decisão (subdimensões 1.1 e 1.2) (H1), foi realizada a análise de variância (ANOVA), técnica estatística que possibilita avaliar se existe diferença significativa entre as médias.

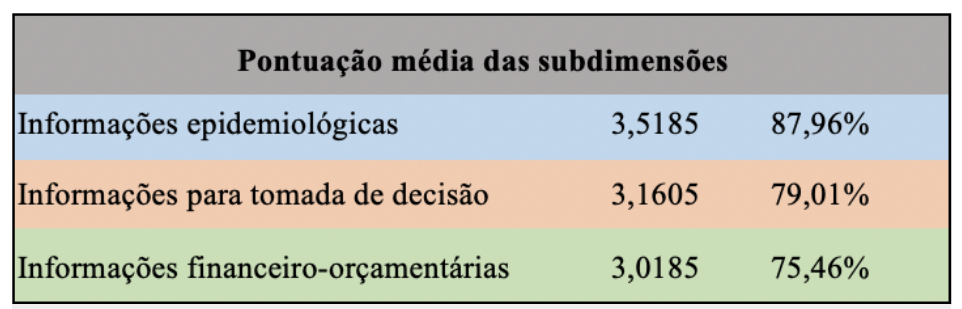

Tabela 6. Pontuação média das subdimensões. Fonte: Elaboração própria das autoras.

\begin{tabular}{|l|l|l|l|l|l|}
\hline Fonte da variação & SQ & gl & MQ & F. calculado & F. crítico \\
\hline Entre grupos & 0,442816667 & 1 & 0,442816667 & $\mathbf{0 , 8 6 7 9 6 5 6 5 7}$ & $\mathbf{4 , 0 2 6 6 3 1 4}$ \\
\hline Dentro dos grupos & 26,52923704 & 52 & 0,510177635 & & \\
\hline Total & 26,9720537 & 53 & & & \\
\hline
\end{tabular}

Tabela 7. Teste Anova. Fonte: Elaboração própria das autoras.

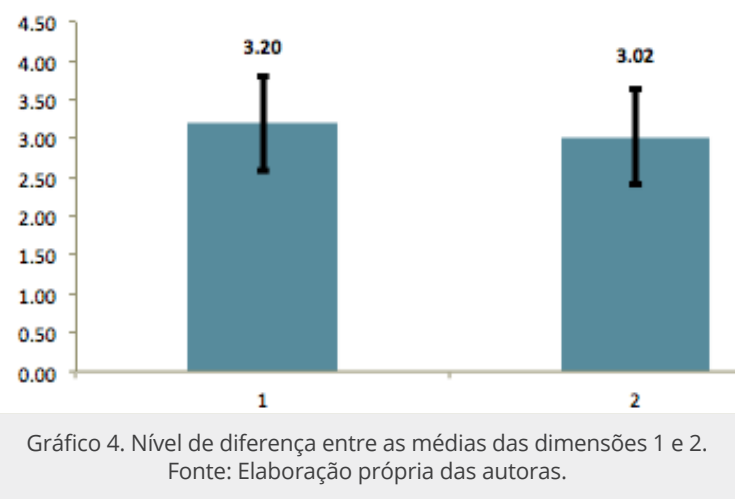


Conforme resultados obtidos pelo teste ANOVA, pode-se afirmar que não há diferença relevante estatisticamente entre as médias, o que rejeita $\mathrm{H} 1$ (conforme a Tabela 7, of_calculado é menor que of_tabelado, o que revela que não há diferença significativa entre elas). Assim, a análise realizada demonstra que as informações financeiro-orçamentárias obtiveram médias iguais às médias das informações epidemiológicas e informações para a tomada de decisão.

Apesar de não apresentarem diferenças estatísticas significativas, há que se considerar, conforme já tratado anteriormente, que as informações epidemiológicas e informações para a tomada de decisão encontradas nas avaliações dos portais apresentaram diferenças quanto à qualidade e ao volume. Isso demonstra que, mesmo que já exista, no Brasil, desde os anos 2000, normas legislativas que preveem a transparência fiscal de municípios, estados e federação, por meio da publicação, com atualizações frequentes, de informações financeiro-orçamentárias da administração pública, materializadas na Lei Complementar $n^{\circ}$ 101/2000 (Lei de Responsabilidade Fiscal - LRF) e na Lei Complementar nº. 131/2009 (conhecida como Lei da Transparência), não se verifica o mesmo sobre informações financeiro-orçamentárias relacionadas à pandemia da COVID-19 nos estados e no DF. Ao contrário do esperado, os estados brasileiros publicam mais informações sobre dados da pandemia (informações epidemiológicas, como casos confirmados, óbitos, etc.) e dados que auxiliam a tomada de decisão por parte dos gestores (ocupações de leitos, boletins diários, etc.) do que informações financeiro-orçamentárias.

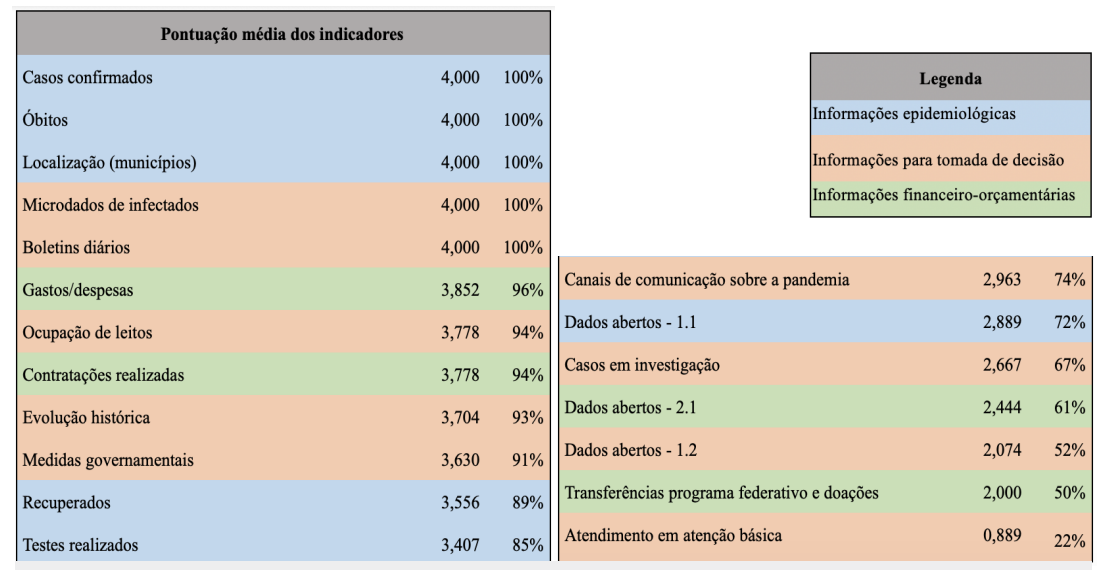

Tabela 8. Pontuação média dos indicadores. Fonte: Elaboração própria das autoras.

Conforme a Tabela 8, todos os estados apresentaram dados atualizados sobre casos confirmados, número de óbitos, localização dos casos (distribuição por 
municípios), microdados de infectados e boletins diários atualizados a cada 24h durante o período de análise. Vale ressaltar, no entanto, que no quesito relativo aos microdados dos infectados, a ausência de informações sobre raça foi notada em diversos estados. Apesar desta ausência isoladamente não implicar em diminuição da nota, a falta desta informação dificulta análises sobre impactos diferenciais da doença em setores específicos da população.

Três desses indicadores, a saber, casos confirmados, óbitos e localização dos casos, fazem parte da subdimensão 1.1, relativa às informações epidemiológicas. O fato destes indicadores terem obtido nota máxima fez com que essa subdimensão obtivesse a maior média, quando comparada à 1.2 (Informações para tomada de decisão) e à 2.1 (Informações financeiroorçamentárias). A subdimensão 1.1 obteve média 87,96\%, o que significa dizer que oito em cada dez estados obtiveram pontuações máximas nos indicadores que a compõem.

Parte da explicação para essa média de destaque nos resultados guarda relação com um indicador da subdimensão 1.2: boletins diários. A quase totalidade dos estados apresentou informações relativas a esses três indicadores por meio da divulgação dos boletins diários que, como demonstra a Tabela 8, teve presença absoluta nas iniciativas analisadas de todos os entes federados. O mesmo pode ser verificado com as informações relativas ao indicador microdado de infectados, da subdimensão 1.2, que também teve $100 \%$ de presença entre os estados e costuma ser divulgado nos boletins diários. Talvez seja possível afirmar que os boletins diários sejam o instrumento com maior carga e importância informativa para a Dimensão 1.

Os dados nos revelam também que as médias dos dados abertos, nas três subdimensões, são relativamente baixas. O percentual de estados que fornencem dados em formato aberto sobre informações epidemiológicas (subdimensão 1.1) é de 72\%, ao passo que os percentuais de estados que oferecem dados em formato aberto sobre informações de saúde para tomada de decisão (subdimensão 1.2) e informações financeiro-orçamentárias (subdimensão 2.1) são ainda menores: 52\% e 61\%, respectivamente.

Sobre as informações financeiro-orçamentárias, embora a média de estados que divulgam gastos/despesa e contratações realizadas seja alta (96\% e 94\%, respectivamente), poucos são os que divulgam informações sobre a transferência de programas federativos e doações. O baixo índice de presença desse tipo de dado denota um ponto-cego importante no que diz respeito à transparência orçamentária dos estados no combate à pandemia (Tabela 9). 


\section{Transferências de programas federativos e doações}

$\begin{array}{llr}\text { AM, DF, MA, PB, PE, PR, RR, SC, SE, SP, TO } & 4 & 100,00 \% \\ \text { ES, PA, RO } & 2 & 50,00 \% \\ \text { AC, AL, AP, BA, CE, GO, MG, MS, MT, PI, RJ } & 0 & 0,00 \%\end{array}$

Tabela 9. Desempenho dos estados no indicador Transferências de programas federativos e doações. Fonte: Elaboração própria das autoras.

Cabe ressaltar também o baixo grau de transparência de informações relativas ao indicador atendimento em atenção básica, que se explica em razão do pouco investimento dos estados em discriminar informações sobre ocupação de leitos e tratamento em Unidades de Pronto Atendimento e outras unidades de atenção básica. A ausência dessa informação é também sinal da falta de centralidade do sistema de saúde de baixa complexidade no combate à pandemia no caso brasileiro, onde foram privilegiados os investimentos em unidades de alta complexidade e de funcionamento temporário (hospitais de campanha). A dificuldade de acesso a informações precisas também se mostrou no quesito "testes", dado que muitos estados não diferenciam os tipos de testes realizados e suas respectivas quantidades.

Vale ainda destacar que $74 \%$ das unidades da federação criaram canais de comunicação específicos para questões relacionadas à COVID-19. Esses canais variam bastante em formato: são desde e-mails e formulários on line até aplicativos em que os cidadãos podem informar sintomas e obter orientações. Já a publicação das medidas governamentais relativas à pandemia aparecem na quase totalidade dos casos (91\%), apesar de nem sempre serem oferecidas de forma a facilitar o acesso.

\section{Nível de transparência e sua correlação com as variáveis socioeconômicas e epidemiológicas}

Buscamos avaliar se, e de que maneira, variáveis socioeconômicas (IDH, PIB, renda mensal, densidade populacional) e epidemiológicas (óbitos, casos por 100 mil habitantes, testes por 100 mil habitantes e letalidade) podem explicar o índice de transparência das informações epidemiológicas e financeiro-orçamentárias da pandemia COVID-19 dos governos estaduais e DF. Para tanto, apresentamos aqui os resultados do teste das hipóteses 2 e 3 , alcançados por meio da análise de regressão linear simples (correlação de Pearson) e da análise multivariada.

Inicialmente, procedeu-se ao cálculo do coeficiente de correlação de Pearson para verificar a relação entre as variáveis. Na tabela 10, verifica-se que IDH, 
testes $100 \mathrm{k}$ e PIB demonstraram ter maior relação linear positiva forte com a variável dependente transparência $C O V I D^{7}$.

\begin{tabular}{|l|c|c|c|c|c|c|c|c|}
\hline $\begin{array}{l}(\rho) \text { Transparência } \\
\text { COVID }\end{array}$ & IDH & PIB & $\begin{array}{c}\text { Renda } \\
\text { mensal }\end{array}$ & $\begin{array}{c}\text { Densidade } \\
\text { populacion } \\
\text { al }\end{array}$ & Óbitos & $\begin{array}{c}\text { Casos } \\
\mathbf{1 0 0 k}\end{array}$ & $\begin{array}{c}\text { Testes } \\
\mathbf{1 0 0 k}\end{array}$ & $\begin{array}{c}\text { Letalidad } \\
\text { e }\end{array}$ \\
\cline { 2 - 8 } & 0.9763 & 0.7148 & 0.4676 & 0.3576 & 0.4245 & 0.1315 & 0.8542 & 0.5783
\end{tabular}

Tabela 10. Coeficiente de correlação das variáveis. Fonte: Pesquisa de campo realizada entre os dias 01/06/2020 e 12/06/2020.

Para aperfeiçoar a capacidade de predição e compreender ao mesmo tempo os efeitos de duas ou mais variáveis independentes sobre uma variável dependente procedeu-se a regressão linear múltipla para identificar o modelo que melhor explicasse o comportamento da "transparência COVID" e permitisse testar $\mathrm{H} 2$ e H3. Assim, realizamos outros testes utilizando várias combinações das variáveis independentes. Contudo, a única combinação que demonstrou significância e portanto, melhor condição explicativa, conforme a Tabela 11, está representada pela equação (modelo abaixo):

$$
\text { ItransparênciaCOVID = 28,5161 + (-35,93xIDH })+(0,003 x \text { renda })+\varepsilon
$$

\begin{tabular}{|c|c|c|c|c|}
\hline \multicolumn{5}{|c|}{$\operatorname{lm}($ formula $=$ trans $\sim \mathrm{idh}+$ renda $)$} \\
\hline \multicolumn{5}{|l|}{ Residuals: } \\
\hline Min: -1.93222 & 1Q: -0.71710 & Median: -0.05606 & 3Q: 0.87011 & Max: 2.07530 \\
\hline \multicolumn{5}{|l|}{ Coefficients: } \\
\hline & Estimative & Std. Error & T value & $\operatorname{Pr}(>|\mathbf{t}|)$ \\
\hline (Intercept) & 28.516141 & 8.327870 & 3.424 & $0.00222 * *$ \\
\hline IDH & -35.939866 & 14.241583 & -2.524 & $0.01865 *$ \\
\hline Renda & 0.003903 & 0.001472 & 2.651 & $0.01398 *$ \\
\hline \multicolumn{5}{|c|}{ Signif. codes: $0^{\prime * * *} 0.001^{\prime * *} 0.011^{\prime *}, 0.05$ '’ $0.1 \stackrel{\text { ‘ }}{=} 1$} \\
\hline \multicolumn{5}{|c|}{ Residual standard error: 1.14 on 24 degrees of freedom } \\
\hline \multicolumn{5}{|c|}{ Multiple R-squared: 0.2265} \\
\hline
\end{tabular}

Tabela 11. Resumo dos resultados da análise de regressão linear múltipla. Fonte: Pesquisa de campo realizada entre os dias 02/06/2020 a 20/06/2020.

7 Em estudo realizado por Amorim (2012) para verificar o nível de transparência digital das capitais brasileiras e a sua correlação com indicadores socioeconômicos, as variáveis IDH e PIB também apresentaram forte poder preditivo na correlação de Pearson. No entanto, na análise de regressão multivariada, apenas as variáveis inserção digital (não avaliada neste estudo) e PIB revelaram-se explicativas da transparência digital das capitais. 
Isso significa que $\mathrm{H} 2$, conforme modelo explicativo, confirma-se parcialmente, já que apenas dois dos quatro indicadores socioeconômicos (IDH, $\mathrm{PIB}$, renda mensal e densidade populacional) foram capazes de explicar a variável dependente (índices de transparência COVID), sendo eles IDH e renda mensal. O IDH mostrou-se ser a variável independente com maior poder preditivo e maior sensibilidade para influenciar o índice de transparência $(-35,93 \%)$ e a variável rendimento mensal teve poder preditivo incremental de $0,0039 \%{ }^{8}$. Cabe destacar que, embora o valor encontrado para a variável rendimento mensal seja numericamente pequeno, ele é estatisticamente significativo (grau de confiança de 95\%). A significância encontrada, mesmo obtendo um valor de baixa magnitude, é explicada pelo tamanho da amostra da pesquisa $(n=28)$. As outras variáveis não apresentaram nenhuma significância, assim, caso haja replicação deste estudo a equação encontrada é a que terá capacidade explicativa. No que diz respeito à variável da renda mensal, os resultados apresentados seguem uma tendência verificada em outros estudos acerca da relação da transparência pública e o desenvolvimento econômico (AMORIM, 2012): o incremento da renda mensal aponta positivamente para a melhoria dos índices de transparência dos governos estaduais. Em princípio, cogita-se existir alguma relação entre renda e transparência pública. Ou seja, presume-se que estados com maior renda média mensal, o que representa melhor desenvolvimento econômico, recebem mais demanda por transparência pública. No caso deste estudo, verificou-se um poder incremental entre a renda mensal e a transparência dos entes federativos em relação às informações sobre a pandemia da COVID-19.

No entanto, de acordo com o modelo explicativo, quanto maior o IDH do estado, menor seu nível de transparência. Trata-se de um cenário intrigante que pode suscitar tanto questionamentos acerca de seu poder de esclarecimento - afinal, pode-se argumentar em favor da improbabilidade de um baixo índice de desenvolvimento humano permitir e/ou estimular maior transparência de estados sobre a pandemia - quanto especulações mais favoráveis a seu poder explicativo, uma vez que gestores e a própria estrutura burocrática de estados mais pobres e desiguais possam encarar a crise com maior gravidade e, consequentemente, produzir mais e melhor informação sobre a situação do ente federativo frente à pandemia.

8 O poder preditivo representa o percentual de sensibilidade para influenciar o índice de transparência COVID dos estados. Assim, com o acréscimo de uma unidade do IDH, teremos o decréscimo de -35.9399 na transparência COVID. O poder preditivo incremental (0,0039\%) representa o percentual de sensibilidade para influenciar o índice de transparência COVID dos estados. Assim, o acréscimo de uma unidade do rendimento mensal, teremos o acréscimo de 0.0039 na transparência COVID. 
Já H3 não se confirma, pois as análises feitas com as demais variáveis escolhidas (incluídas as variáveis epidemiológicas) para este estudo não apresentaram valores significativos que permitissem considerá-los na construção do modelo explicativo.

\section{Conclusão}

O presente trabalho teve como principal objetivo avaliar quais os níveis de transparência de dados e informações dos governos estaduais e do DF em relação à crise da COVID-19. Após o desenvolvimento de um instrumento metodológico elaborado especificamente para este fim e aplicado aos portais dos governos estaduais e DF, concluímos que, com exceção do Amapá, que apresenta transparência fraca, os estados se dividiram igualmente em transparência avançada (nível da transparência entre 80\% e 100\%) e transparência moderada (nível da transparência varia 60 e 79,99\%).

Foram avaliadas informações relacionadas: (i) aos dados epidemiológicos, como o número de casos confirmados, casos em investigação, pacientes recuperados e óbitos; (ii) aos dados que auxiliam gestores a tomarem decisões sobre como proceder em relação à pandemia, como, por exemplo, a ocupação de leitos - o que ajuda o gestor público sociedade civil a se posicionarem e decidirem sobre continuidade do isolamento, reabertura do comércio, etc.; e (iii) informações financeiro-orçamentárias, que abrangem contratações emergenciais, doações e transferências de recursos destinadas ao combate à pandemia.

Pelo fato de já haver, no Brasil, previsões normativas que asseguram o provimento da transparência sobre informações financeiro-orçamentárias, bem como de o Governo Federal ter regulamentado a Lei Federal $n^{\circ}$ 13.979/2020, que versa sobre as contratações emergenciais de bens e serviços para a contenção da COVID-19 e prevê a promoção a transparência para as informações relativas às contratações realizadas neste cenário de excepcionalidade (art. $4 \S 20$ ), supomos que a dimensão de análise que compreende esse tipo de informação receberia uma nota superior àquelas referentes às informações epidemiológicas e para tomada de decisão $(\mathrm{H} 1)$. No entanto, não foi o que mostrou o estudo.

Embora o teste da hipótese tenha revelado que a diferença de pontuação entre as dimensões não é significativa, a análise segregada das dimensões, das subdimensões e dos indicadores mostrou que os entes federativos 
dispõem de investimento maior na produção e divulgação atualizada de informações epidemiológicas do que na produção de transparência financeira em relação à pandemia. Este resultado aponta para uma grande preocupação dos estados em prover aos cidadãos e veículos de comunicação informações atualizadas sobre dados epidemiológicos da pandemia, como números de casos e óbitos. Uma possível explicação para este resultado é, ainda, a demonstração de que a transparência não está entre as prioridades do Governo Federal brasileiro e que um consórcio de veículos de mídia passaram a coletar, diariamente, dados das secretarias de saúde estaduais para informar a população brasileira sobre o estágio da pandemia.

Buscamos averiguar, também, se variáveis socioeconômicas, como IDH, PIB, renda mensal, densidade populacional (H2) e epidemiológicas, como Óbitos, Casos por 100 mil habitantes, Testes por 100 mil habitantes e Letalidade (H3), podem explicar o índice de transparência dos governos estaduais. Nesse sentido, apenas IDH e renda mensal demonstraram capacidade explicativa do nível de transparência dos estados, sendo o resultado do IDH intrigante por revelar que quanto maior o IDH do estado, menor seu nível de transparência. Este fato nos leva a questionar se, diante o contexto da pandemia da COVID-19, gestores públicos e a própria estrutura burocrática dos estados com menos recursos têm produzido mais e melhor informação sobre a situação de seus respectivos estados por encararem a crise com maior gravidade. Esta é uma questão que deve ser considerada e, por isso, recomenda-se a continuação da aplicação deste instrumento metodológico (ou outros com a mesma finalidade), para que se possa aferir com mais precisão (longitudinalmente, por exemplo) sobre a relação entre IDH e transparência de entes federativos.

Por fim, os resultados desta pesquisa demonstram que, de forma quase absoluta, os estados brasileiros e o DF têm apresentado índices de transparência relevantes e destacados em termos gerais, visto que toda a amostra, com exceção do estado do Amapá, figura, de forma simétrica, entre os dois maiores patamares de transparência presentes no modelo metodológico desenvolvido. Temos, portanto, de forma geral, ofertas "elevadas" e significativas de transparência sobre informações relacionadas à pandemia do coronavírus, o que nos leva a questionar o motivo de uma crise sanitária fazer com que os estados produzam mais informações, resultando em maior transparência. A resposta pode estar no fato de que, neste contexto, toda a atenção pública (ou grande parte dela) está voltada especificamente para 
este assunto. Esta atenção pública poderia, portanto, agir de modo a pressionar gestores públicos a serem mais transparentes sobre dados e números, tomadas de decisão e informações fiscais relacionadas à pandemia.

Se, por um lado, o indicador que avalia o grau de transparência dos estados sobre as transferências de programas federativos e doações foi o que obteve a segunda pior pontuação, por outro, sabemos que é a transparência sobre dados e informações o primeiro passo para a accountability, que pode ser considerada o grau máximo da transparência e se caracteriza pela possibilidade de constrangimento causada pela transparência, somada à perspectiva de sanção sobre o agente. No contexto da pandemia da COVID-19 no Brasil há investigações e inquéritos em curso que versam sobre o modo como gestores estaduais têm gerido verbas da federação destinadas ao combate à pandemia, o que tem levado estes atores a irem a público ou se reportarem a instâncias do próprio Estado e, também, aos cidadãos, a fim de justificar suas decisões e receber punições ou constrangimentos em casos de desvios e irregularidades. Esses casos demonstram a importância da divulgação de dados e informações financeiro-orçamentárias relacionados à pandemia pelos estados, embora não seja possível, por meio do estudo aqui realizado, afirmar que há uma causalidade entre a transparência dos estados sobre informações relacionadas à pandemia e as investigações sobre os casos de corrupção em compras e aquisições realizados durante essa crise sanitária.

Ademais, estimamos que o modelo metodológico, as análises e os resultados apresentados neste estudo sejam úteis para o desenvolvimento de pesquisas longitudinais com a finalidade de aferir a manutenção do comportamento das variáveis ou de pesquisas futuras que busquem avaliar outros aspectos que ajudem na compreensão da relação entre transparência pública e a COVID-19.

Maria Paula Almada é pesquisadora pós-doc (bolsista CAPES) do Instituto Nacional de Ciência e Tecnologia em Democracia Digital (INCT-DD) e Doutora em Comunicação e Cultura Contemporâneas (Facom/UFBA) na linha de comunicação e política, tendo realizado estágio-doutoral na School of Public Affairs and Administration, Rutgers University (EUA), além de estágio de pesquisadora visitante no Instituto de Ciências Sociais da Universidade de Lisboa. É vice-coordenadora do Grupo de Trabalho "Governo e Parlamento Digital" da Associação Brasileira de Pesquisadores em Comunicação e Política (Compolítica)

mariapaula.almada@gmail.com 
Camilo Aggio é professor adjunto do Departamento de Comunicação Social da UFMG e professor colaborador do PPGCOM da mesma instituição. É pesquisador associado ao Instituto Nacional de Ciência e Tecnologia em Democracia Digital (INCT.DD) e membro do Grupo de Pesquisa em Justiça e Democracia (MARGEM). É doutor em Comunicação e Cultura Contemporâneas pelo POSCOM/UFBa.

camiloaggio@gmail.com

Paula Karini Amorim é doutora em Comunicação e Cultura Contemporâneas pela Universidade Federal da Bahia e pesquisadora associada do Instituto Nacional de Ciência e Tecnologia em Democracia Digital (INCT-DD). É professora da Área de Gestão e Negócios e atualmente é pró-reitoria de Pesquisa, Pós-graduação e Inovação do Instituto Federal do Tocantins (IFTO).

paula.karini@gmail.com

Nina Santos é pós-doutoranda no Instituto Nacional de Ciência e Tecnologia em Democracia Digital e pesquisadora associada do Centre d'Analyse et de Recherche Interdisciplinaires sur les Médias (Université Paris II). Foi pesquisadora visitante no Center of Advanced Internet Research (CAIS - Alemanha, 2020) e no grupo Social Movements in the Global Age, na Université de Louvainla-Neuve (SMAG - Bélgica, 2018). Sua tese de doutorado, defendida na Université Paris II, foi premiada com o Prix de thèse da instituição e indicada ao Prix de la Chancellerie des Universités de Paris.

nina.santos@inctdd.org

Maria Dominguez Costa Pinho é pesquisadora do Instituto Nacional de Ciência e Tecnologia em Democracia Digital (INCT.DD). É mestre em Comunicação e Cultura Contemporâneas pela Universidade Federal da Bahia e jornalista pela mesma instituição.

mariadominguezcp@gmail.com 
Contribuições de cada autor: Maria Paula Almada: supervisão e gestão do Projeto de Pesquisa, fundamentação teórica e conceituação, curadoria de dados, escrita - primeira redação, revisão e edição, investigação de campo, metodologia. Camilo Aggio: fundamentação teórica e conceituação, escrita - redação, revisão, descrição dos resultados, análises dos dados, investigação de campo, análise formal do corpus. Paula Karini Amorim: curadoria de dados, escrita - primeira redação, revisão e edição, metodologia, análise formal do corpus, gestão de software, construção de figuras e tabelas. Nina Santos: fundamentação teórica e conceituação, curadoria de dados, escrita - primeira redação, revisão e edição, investigação de campo, análise formal do corpus, construção de figuras e tabelas. Maria Dominguez Costa Pinho: fundamentação teórica e conceituação, curadoria de dados, escrita - primeira redação, revisão e edição, metodologia, análise formal do corpus.

\section{Referências}

ALMADA, M. P. Avaliação da Etransparência em Portais De Governos Nacionais: Uma Comparação entre Brasil, Estados Unidos e Reino Unido. 2017. Tese de Doutorado defendida junto ao Programa de Pós Graduação em Comunicação e Cultura Contemporâneas da Universidade Federal da Bahia, Salvador, 2017. Disponível em: <https://www.academia.edu/35420388/ AVALIAÇÃO_DA_ETRANSPARÊNCIA_EM_PORTAIS_DE_GOVERNOS_NACIONAIS_UMA_ COMPARAÇÃO_ENTRE_BRASIL_ESTADOS_UNIDOS_E_REINO_UNIDO>. Acesso em: 07 jun. 2021.

ALWAN, N. et al. Evidence informing the UK's COVID-19 public health response must be transparent. The Lancet, v. 395, n. 10229, p. 1036-1037, 2020.

BALDISSERA, J. F. et al. Influência dos aspectos socioeconômicos, financeiro-orçamentários e político-eleitorais na transparência dos governos locais. Revista de Administração Pública, v. 54, n. 2, p. 340-359, 2020.

BARTON, C. M. et al. Call for transparency of COVID-19 models. Science, v. 368, n. 6490, p. $482-483,2020$.

AMORIM, P. K. Democracia e Internet: A Transparência de Gestão Nos Portais Eletrônicos Das Capitais Brasileiras. 2012. Tese de Doutorado defendida junto ao Programa de Pós Graduação em Comunicação e Cultura Contemporâneas da Universidade Federal da Bahia, Salvador, 2012. 
BRASIL. Decreto No 8.777 de 11 de maio de 2016. Brasília, 2016. Disponível em: <http://www.planalto.gov.br/ccivil_03/_Ato2015-2018/2016/Decreto/D8777.htm>. Acesso em: 21 jul. 2020.

. Lei Complementar 101, de 04 de maio de 2000. "Lei de Responsabilidade Fiscal". Disponível em: <http://www.planalto.gov.br/ccivil_03/leis/LCP/Lcp101.htm>. Acesso em: 21 jul. 2020.

Lei Complementar 131, de 27 de maio de 2009. “Lei da Transparênncia”. Disponível em: <http://www.planalto.gov.br/ccivil_03/leis/LCP/Lcp131.htm>. Acesso em: 21 jul. 2020.

. Lei de Acesso à Informação Pública: Lei n 12.527, de 18 de novembro de 2011.Disponível em: <http://www.planalto.gov.br/ccivil_03/_Ato2011-2014/2011/Lei/ L12527.htm>. Acesso em: 21 jul. 2020.

Lei $N^{\circ}$ 13.979, de 6 de fevereiro de 2020. Disponível em: <http://www.planalto. gov.br/ccivil_03/_ato2019-2022/2020/lei/l13979.htm> Acesso em: 21 jul. 2020.

CHENG, Z. J.; SHAN, J. 2019 Novel coronavirus: where we are and what we know. Infection, v. 48, p. 155-163, 2020.

GAO, X.; YU, J. Public governance mechanism in the prevention and control of the COVID-19: information, decision-making and execution. Journal of Chinese Governance, v. 5, p. 178-197, 2020.

GOMES, W., AMORIM, P.K., ALMADA, M.P. Novos Desafios Para a Ideia de Transparência Pública._E-Compós: Revista da Associação Nacional dos Programas de Pós-Graduação, v. 21, n. 2, p. 21, 2018.

HENKE, N.; KELSEY, T. Transparency - the most powerful driver of health care improvement? Health International, v. 11, p. 64-73, 2011.

LA, V. P. et al. Policy Response, Social Media and Science Journalism for the Sustainability of the Public Health System Amid the COVID-19 Outbreak: The Vietnam Lessons. Sustainability, v. 12, n. 7, p. 2931, 2020.

MACHADO, C.; SANTOS, J. G.; SANTOS, N.; BANDEIRA, L. Scientific [Self] Isolation. São Paulo: LAUT, 2020. Disponível em: <https://laut.org.br/scientific-self-isolation>. Acesso em: 5 abr. 2021.

O'MALLEY, P.; RAINFORD, J.; THOMPSON, A. Transparency during public health emergencies: From rhetoric to reality. Bulletin of the World Health Organization, v. 87, p. 614-618, 2009.

OJIAGU, N.; NZEWI, H.; ARACHIE, A. Accountability And Transparency In Nation Building: A Covid-19 Experience In Sub-Saharan Africa. International Journal of Public Policy and Administration Research, v. 7, n. 1, p. 23-33, 2020. 
RAHIMI, F.; ABADI, A. T. B. Transparency and information sharing could help abate the COVID-19 pandemic. Infection Control \& Hospital Epidemiology, v. 41, n. 11, p. 1366-1367, 2020.

RAJAN, D. et al. Governance of the Covid-19 response: a call for more inclusive and transparent decision-making. BMJ Global Health, v. 5, n. 5, p. e002655, 2020.

RECUERO, R.; SOARES, F. O Discurso Desinformativo sobre a Cura do COVID-19 no Twitter: Estudo de caso. E-Compós, 2021.

SRIDHAR, D.; BATNIJI, R. Misfinancing global health: a case for transparency in disbursements and decision making. The Lancet. v.372, n. 9644, p. 1185-1191, 2008.

Artigo recebido em 27/02/2021 e aprovado em 06/06/2021. 